\title{
A protocol for direct somatic embryogenesis of Protea cynaroides L. using zygotic embryos and cotyledon
} tissues

\section{H. C. Wu ${ }^{1}$, E. S. du Toit ${ }^{1}$ and C. F. Reinhardt ${ }^{1}$}

1. Department of Plant Production and Soil Science, Faculty of Natural and Agricultural Sciences, University of Pretoria, Pretoria, 0002, South Africa

\begin{abstract}
We describe a protocol for somatic embryogenesis of Protea cynaroides, with potential for high frequency production of this important horticultural species. Somatic embryos formed directly on both $P$. cynaroides mature zygotic embryos and excised cotyledons cultured on MS medium without growth regulators. The addition of growth regulators such as naphthalene acetic acid (NAA) $(5 ; 13$ and $27 \mu \mathrm{M})$ and 2,4-dichlorophenoxyacetic acid $(2,4-\mathrm{D})(5 ; 11$ and $23 \mu \mathrm{M})$, in combination with thidiazuron (TDZ) $(1 \mu \mathrm{M})$, benzylaminopurine (BAP) $(1 \mu \mathrm{M})$ or kinetin $(1 \mu \mathrm{M})$ suppressed the formation of somatic embryos. After eight weeks in culture, formation of somatic embryos was observed. Zygotic explants formed the most embryos when cultured in a 12-h photoperiod in comparison to explants cultured in the dark. Up to $83 \%$ of these embryos germinated after transferal to the germination medium containing $0.3 \mu \mathrm{M} \mathrm{GA}_{3}$. Significantly fewer embryos germinated in MS medium with no growth regulators, or supplemented with higher concentrations of $\mathrm{GA}_{3}$, while low germination percentages were also observed in MS media containing casein hydrolysate and coconut water. The germination of normal somatic embryos (two separate cotyledons and a single radicle) was observed only in media containing either no growth regulators, $0.3 \mu \mathrm{M} \mathrm{GA}_{3}$ or $1 \mu \mathrm{M} \mathrm{GA}_{3}$. All embryos that germinated in high concentrations of $\mathrm{GA}_{3}$ were malformed.
\end{abstract}


Abbreviations 2,4D 2,4-Dichlorophenoxyacetic acid - BAP 6-Benzylaminopurine $G A_{3}$ Gibberellic acid - NAA 1-Naphthalene acetic acid - PAR Photosynthetic active radiation - TDZ Thidiazuron

\section{Introduction}

Protea cynaroides, known as the King Protea, is endemic to South Africa. It is an important cutflower in the local and export market. Current propagation methods of $P$. cynaroides through seeds and cuttings are slow and inconsistent (Wu 2006), thus, alternative propagation methods are needed to improve the success rate and reduce the time required to obtain rooted plantlets. Plant regeneration via somatic embryogenesis has the potential to produce a large number of plantlets in a relatively short period of time. Although numerous plant species are reportedly capable of forming somatic embryos, very few reports of somatic embryogenesis have been documented for members of the Proteaceae family. In the Protea genus only Protea repens has been reported to form somatic embryos (Rugge 1995). Van Staden et al. (1981) were able to induce callus and proteoid rootlet formation in Protea neriifolia, but attempts to initiate shoot and root development were unsuccessful. In other Proteaceae species, the commercially-important Serruria florida was induced to form somatic embryos (Rugge et al. 1989).

The slow growth of established explants, as well as their inability to form roots, are stumbling blocks encountered during micropropagation of $P$. cynaroides (Wu et al. 2004). This was shown by Ben-Jaacov and Jacobs (1986) and Wu and du Toit (2004), where $P$. cynaroides explants were established successfully in vitro by inducing axillary buds to sprout, however, in vitro rooting was unsuccessful. In addition, phenolic oxidation of explants of $P$. cynaroides has been reported to be a problem (Wu and du Toit 2004), which resulted in their death. Thus, somatic embryogenesis has potential as an alternative in vitro propagation method for $P$. cynaroides production.

The main objective of this preliminary study was to investigate and determine a suitable explant, optimum growth conditions and culture medium for the induction, development and germination of somatic embryos. 


\section{Materials and methods}

\section{Plant materials}

Excised, mature zygotic embryos and cotyledons from in vitro-germinated seedlings were used as source material for the induction of somatic embryos. Excision of the zygotic embryos was done by first removing the hairs on the seeds by hand. The seeds were then surface-sterilized in $0.35 \%(\mathrm{v} / \mathrm{v})$ sodium hypochlorite $(\mathrm{NaOCl})$ for $5 \mathrm{~min}$, followed by three mins in concentrated sulphuric acid $\left(\mathrm{H}_{2} \mathrm{SO}_{4}\right)$. Thereafter, the seeds were stirred in sterilized distilled water for $10 \mathrm{~min}$. Each seed coat was then cut open and the embryo removed and placed into the induction medium.

To obtain cotyledons from in vitro-germinated seedlings, seeds were sterilized as described above, and placed onto the germination medium. The germination medium contained half-strength Murashige and Skoog (MS) medium (Murashige and Skoog 1962) supplemented with $3 \%(\mathrm{w} / \mathrm{v})$ sucrose and Gelrite ${ }^{\circledR}\left(3 \mathrm{~g} \mathrm{l}^{-1}\right)$. Ten ml of medium were dispensed into $50 \mathrm{~cm}^{3}$ glass test tubes. The $\mathrm{pH}$ of the medium was adjusted to 5.7 before autoclaving. The medium was autoclaved at $104 \mathrm{KPa}$ at $121^{\circ} \mathrm{C}$ for $20 \mathrm{~min}$. The zygotic embryos were germinated in a growth chamber under cool, white fluorescent tubes which provided $60 \mu \mathrm{M} \mathrm{m}^{-2} \mathrm{~s}^{-1}$ PAR. A 12-h photoperiod was used and the temperature of the growth chamber was adjusted to $21 \pm 2 / 12 \pm 2{ }^{\circ} \mathrm{C}$. Germination of the zygotic embryos was observed after 30 days in culture. The cotyledons obtained from the newly in vitro-germinated seedlings were cut into similar sizes $(5 \mathrm{~mm} \times 5 \mathrm{~mm})$ and then placed on their adaxial side on the induction medium.

\section{Culture media and growth conditions}

For the induction of somatic embryos, full-strength MS medium containing 3\% (w/v) sucrose and Gelrite ${ }^{\circledR}\left(3 \mathrm{~g} \mathrm{l}^{-1}\right)$ was used as the basal medium. 2,4-D $(5 ; 11$ and $23 \mu \mathrm{M})$ and NAA $(5 ; 13$ and $27 \mu \mathrm{M})$ were either added singly or in combination with the following: TDZ $(1 \mu \mathrm{M})$, BAP $(1 \mu \mathrm{M})$, or kinetin $(1 \mu \mathrm{M})$. Other media supplements included coconut water $\left(50\right.$ and $\left.100 \mathrm{ml} \mathrm{l}^{-1}\right)$, and casein hydrolysate $\left(100 \mathrm{mg} \mathrm{l}^{-1}\right.$ and $\left.200 \mathrm{mg} \mathrm{l}^{-1}\right)$, which were added singly into the basal medium containing no growth regulators. In addition, 
full-strength basal MS medium with no growth regulators was used as the control medium.

In the germination study, heart-shaped somatic embryos, which formed in the induction stage, were carefully removed from the source explants and transferred onto germination medium. Half-strength MS medium was used with the following growth regulators added singly: $\mathrm{GA}_{3}(0.3,1,3,7,14,29$ and $58 \mu \mathrm{M})$, casein hydrolysate $\left(100\right.$ and $\left.200 \mathrm{mg}^{-1}\right)$ and coconut water (50 and $100 \mathrm{ml} \mathrm{l}^{-1}$ ). Half-strength basal MS medium with no growth regulators was used as the control medium.

The $\mathrm{pH}$ of all the media was adjusted to 5.7 before autoclaving. The medium was autoclaved at $104 \mathrm{KPa}$ at $121^{\circ} \mathrm{C}$ for $20 \mathrm{~min}$. All growth regulators were autoclaved except $\mathrm{GA}_{3}$, which was filter-sterilized. For the induction medium, each explant was cultured in a glass test tube containing $10 \mathrm{ml}$ of medium. For the germination of somatic embryos, heart-shaped embryos were transferred from the source explants onto autoclave-sterilized filter paper (Whatman ${ }^{\circledR}$ No. 1) lining 90-mm Petri dishes, which contained $25 \mathrm{ml}$ of medium.

For the induction of somatic embryos, the explants were either cultured under a 12-h photoperiod or in total darkness (control) without transfer to fresh medium throughout the entire duration of the study. Data were collected after eight weeks in culture. Illumination was supplied by cool, white fluorescence tubes providing $60 \mu \mathrm{M} \mathrm{m}^{-2} \mathrm{~s}^{-1} \mathrm{PAR}$. For germination, somatic embryos were grown in the dark only. Observation for germination was made after 4 weeks in culture. The temperature was adjusted to $25 \pm 2{ }^{\circ} \mathrm{C}$ for the induction stage, while $21 \pm 2 / 12 \pm 2^{\circ} \mathrm{C}$ was used in the germination stage.

\section{Statistical analysis}

In the somatic embryo induction stage, one explant was cultured in a test tube. Forty explants were used in each medium treatment. A completely randomized design was applied. The number of explants that formed embryos, and the number of embryos formed per explant was recorded. The data for the number of explants that formed 
embryos was categorical, and the two alternative outcomes (formation of somatic embryos, no formation of embryos) were compared among the medium treatments using chi-square contingency table analyses. Differences were considered significant when $P \leq 0.001$. The number of embryos formed per explant in the medium treatments was analyzed using Tukey's Studentized range test. Differences were considered significant when $P \leq 0.05$.

For each medium treatment in the germination stage, thirty embryos in the heart stage were placed in a Petri-dish. The total number of healthy embryos that germinated per treatment was recorded. The alternative outcomes (germination, no germination) were compared and analyzed using chi-square contingency table analyses. The experiment was repeated twice. Data from the second experiment are reported in this paper. All statistical analyses were done in the SAS program (SAS Institute Inc 1996).

\section{Results}

\section{Induction of somatic embryos on zygotic embryos MS medium without growth regulators}

Six weeks after culturing the explants on the induction medium, the first somatic embryos began to appear on the zygotic embryos cultured on full-strength basal MS medium with no growth regulators (Fig. 1). However, the majority of somatic embryos were formed after eight weeks in culture. All of these somatic embryos differentiated directly, without an intermediate callus phase. Somatic embryos formed on edges (Fig. 1A) and the adaxial side (Fig. 1B) of the zygotic embryo. Somatic embryos formed on the basal MS medium under both light (12-h photoperiod) and dark conditions (control), although under light conditions, significantly more $(P \leq 0.001)$ explants formed embryos $(70 \%)$, compared to $37.5 \%$ of explants forming embryos in the dark (Table 1 ). Moreover, significantly more embryos were formed per explant under the light treatment ( $8.67 \pm 1.52$ embryos) than in the dark ( $5.5 \pm 1.49$ embryos) (Table 1). The somatic embryos that formed on these basal MS media were able to develop from the globular through to the heart stages, with some embryos developing further into the torpedo-shape stage (Fig. 1B). 

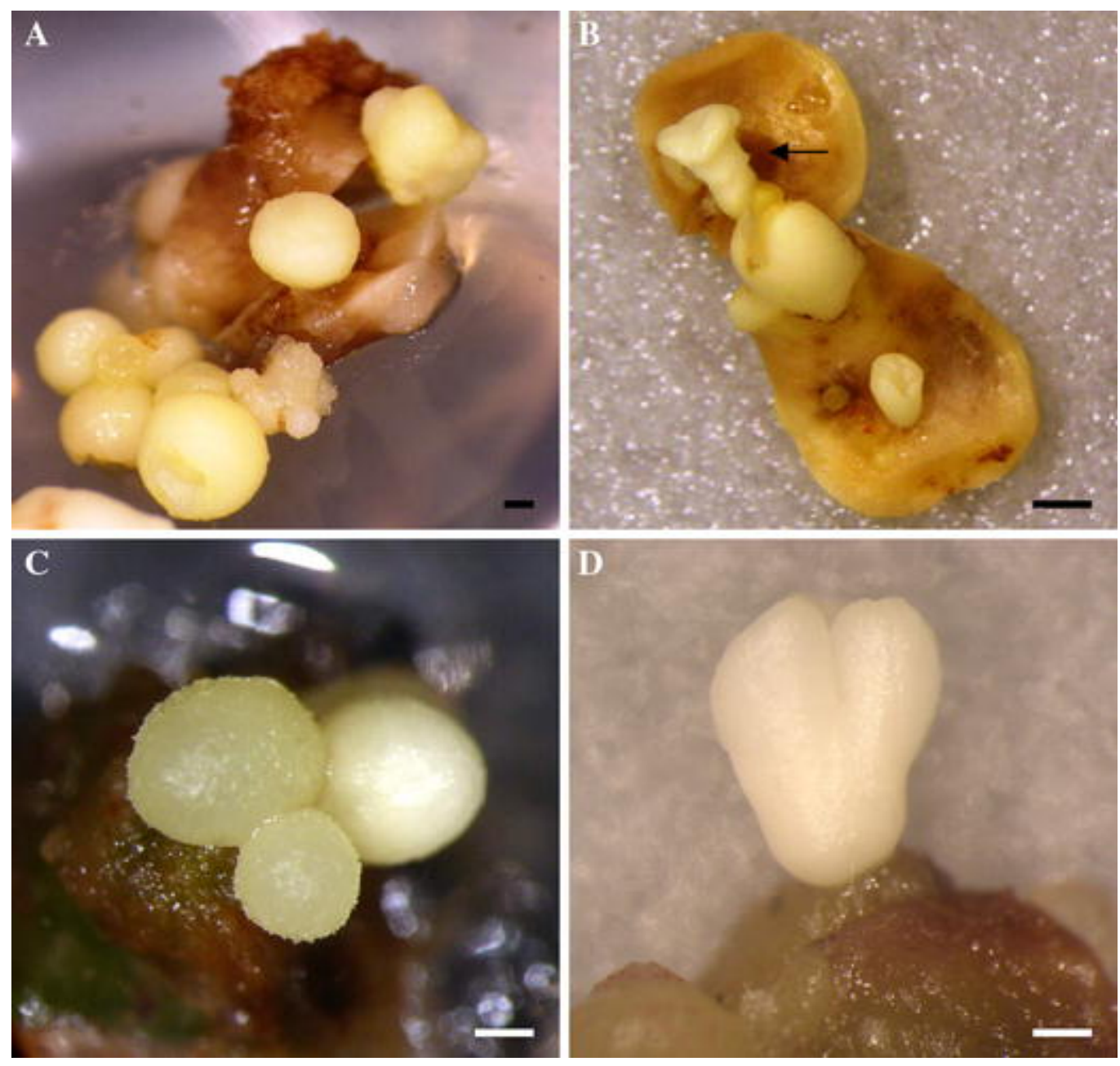

Fig. 1 Direct formation of somatic embryos cultured on full-strength MS medium with no growth regulators: (A) Globular-stage embryos formed on the edges of a zygotic embryo; (B) Torpedo-stage embryo formed on the adaxial side of a zygotic embryo (arrow); (C) Globular-stage embryos on excised cotyledons; (D) The development of somatic embryo into the heart stage directly on excised cotyledons. Bar $\approx 1 \mathrm{~mm}$ 
Table 1 Effects of light conditions on the induction of somatic embryos from zygotic embryos and cotyledons excised from in vitro-germinated seedlings, cultured on fullstrength growth regulator-free MS medium. Data were taken after eight weeks in culture

\begin{tabular}{|l|l|l|l|}
\hline Explant & Photoperiod & $\begin{array}{l}\text { \%o of explants forming } \\
\text { somatic embryos }\end{array}$ & $\begin{array}{l}\text { Mean number of } \\
\text { embryosper explants }\end{array}$ \\
\hline \multirow{2}{*}{ Zygote } & $\begin{array}{l}\text { Control (zero } \\
\text { light) }\end{array}$ & $37.5^{\mathrm{b}}$ & $5.53 \pm 1.49^{\mathrm{b}}$ \\
\hline & $12-\mathrm{h}$ & $70.0^{\mathrm{a}}$ & $8.67 \pm 1.52^{\mathrm{a}}$ \\
\hline \multirow{2}{*}{ Cotyledon } & $\begin{array}{l}\text { Control (zero } \\
\text { light) }\end{array}$ & $22.5^{\mathrm{b}}$ & $4.44 \pm 1.13^{\mathrm{b}}$ \\
\hline & $12-\mathrm{h}$ & $25.0^{\mathrm{b}}$ & $4.10 \pm 1.20^{\mathrm{b}}$ \\
\hline
\end{tabular}

${ }^{x}$ Data were subjected to Chi-Square analysis. Percentages of 40 explants within column followed by different letters are significantly different at $P \leq 0.001$

${ }^{y}$ Means within the same column followed by a different letter are significantly different at $P \leq 0.05$ using Tukey's Studentized range test

\section{MS medium supplemented with growth regulators and other additives}

After eight weeks, somatic embryos also appeared on zygotic embryos cultured in the MS media containing coconut water or casein hydrolysate. However, the number of zygotic explants that formed embryos was less than $10 \%$, and these results were considered insignificant. In addition, all the media containing various concentrations of 2,4-D or NAA, singly or in combination with TDZ, BAP or kinetin, cultured under light or dark treatments did not induce formation of any somatic embryos, nor were there signs of embryogenic callus formation. One exception to this trend was found on MS medium containing $5 \mu \mathrm{M} 2,4-\mathrm{D}$ and $1 \mu \mathrm{M}$ BAP in the dark, where explants showed some form of callus growth, however, no somatic embryos were produced. In general, zygotic embryos cultured on MS medium containing growth regulators or other additives formed fluffy, watery-looking callus. Attempts to induce embryos on these calluses were unsuccessful. Eventually, these calluses turned brown and died after 12 weeks. 


\section{Induction of somatic embryos on cotyledon explants MS medium without growth regulators}

After eight weeks in culture, somatic embryos also formed directly on cotyledonary explants grown on full-strength MS medium lacking growth regulators, under both light and dark conditions (Table 1). These embryos developed through the globular (Fig. 1C) to the heart (Fig. 1D) stages. The percentage of cotyledonary explants that produced embryos was significantly less $(P \leq 0.001)$ than those produced by the zygotic embryo explants cultured on the same medium treatment and light conditions (Table 1). Twentyfive percent and $22.5 \%$ of cotyledons formed embryos in light and dark conditions, respectively. In addition, the number of embryos formed per explant was significantly less than the amount formed on zygotic explants (Table 1).

\section{MS medium supplemented with growth regulators and other additives}

Similar to the zygotic explants, the direct formation of somatic embryos was suppressed by the addition of growth regulators to the culture medium. Only a few watery calluses

formed scantily, and no embryos were induced on the excised cotyledons cultured on any MS medium supplemented with growth regulators. These explants were covered in watery callus, and showed no ability to produce somatic embryos. Furthermore, unlike the zygotic cultures, in light, no embryos were formed in the medium containing coconut milk or casein hydrolysate, while less than $10 \%$ of these explants formed embryos in the dark (data not shown).

\section{Germination of somatic embryos}

Histodifferentiation of somatic embryos from the heart stage to the cotyledonary stage is shown in Fig. 2. Germination of somatic embryos was observed in all the germination media containing different concentrations of the various growth regulators. However, the germination percentage varied widely from $10 \%$ to $83 \%$ (Table 2). Although germination of the embryos was achieved in the medium lacking growth regulators, germination was favored in medium supplemented with $\mathrm{GA}_{3}$. After four weeks in culture, highest germination percentage was observed in the medium containing $0.3 \mu \mathrm{M} \mathrm{GA}_{3}(83.3 \%)$, which was significantly higher $(P \leq 0.001)$ than the medium with $1 \mu \mathrm{M} \mathrm{GA}_{3}(60 \%)$ 
(Table 2). Significantly fewer embryos germinated in media supplemented with higher concentrations (3-58 $\mu \mathrm{M})$ of $\mathrm{GA}_{3}$, casein hydrolysate or coconut water. Furthermore, $70 \%$ of the embryos that germinated in $0.3 \mu \mathrm{M} \mathrm{GA}_{3}$ were normal, i.e., they consisted of two separate cotyledons and a single radicle (Figs. 2B and 2C). Somatic embryos which germinated in the medium containing either no growth regulators or $1 \mu \mathrm{M} \mathrm{GA}_{3}$ produced only $55.6 \%$ and $50 \%$ typical plantlets respectively, while in all the other media treatments the majority of embryos that germinated were malformed (Table 2). The malformed embryos either had single, multiple or fused cotyledons, or fused embryos.
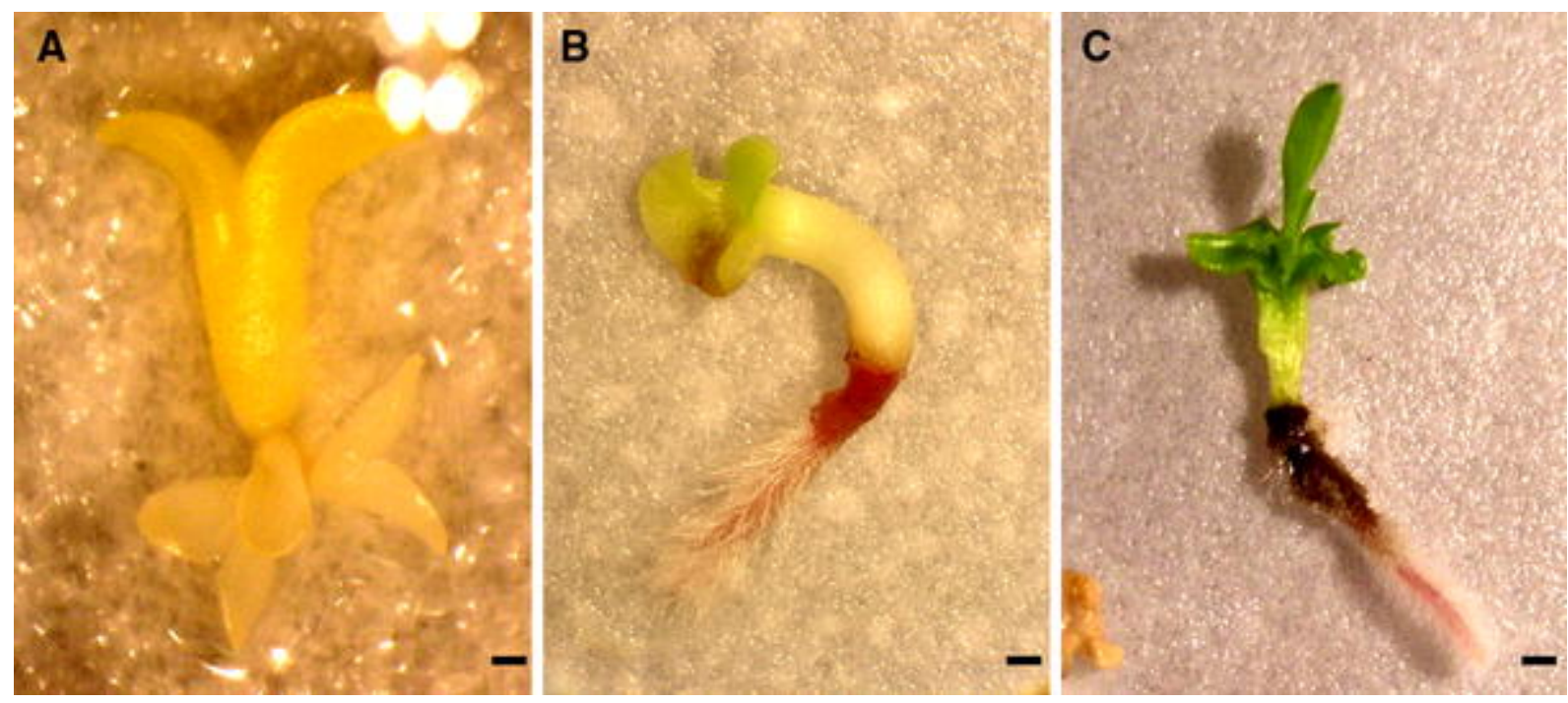

Fig. 2 Development of isolated somatic embryo cultured on germination medium containing MS medium supplemented with $0.3 \mu \mathrm{M} \mathrm{GA}_{3}$. (A) Embryo in cotyledonary stage, with accessory embryos attached; (B) Germination of somatic embryo on MS medium; (C) Emergence of first leaves from the germinated embryo (arrow). Bar $\approx 2 \mathrm{~mm}$ 
Table 2 Effects of growth regulators on the germination of somatic embryos cultured in the dark. Half-strength MS medium was used as the basal medium in all treatments.

Results were taken after four weeks in culture

\begin{tabular}{|c|c|c|c|c|}
\hline $\begin{array}{l}\mathbf{G A}_{3} \\
(\mu \mathrm{M})\end{array}$ & $\begin{array}{l}\text { Casein hydrolysate } \\
\left(\mathrm{mg} \mathrm{l}^{-1}\right)\end{array}$ & $\begin{array}{l}\text { Coconut water } \\
\left(\mathrm{ml} \mathrm{l}^{-1}\right)\end{array}$ & $\begin{array}{l}\text { Total } \\
\text { germination } \\
(\%)^{x}\end{array}$ & $\begin{array}{l}\text { Germination of } \\
\text { normal embryos }^{y} \\
(\%)\end{array}$ \\
\hline Control & & & $30.0^{c}$ & $55.6^{\mathrm{b}}$ \\
\hline 0.3 & - & - & $83.3^{\mathrm{a}}$ & $72.0^{\mathrm{a}}$ \\
\hline 1 & - & - & $60.0^{\mathrm{b}}$ & $50.0^{\mathrm{b}}$ \\
\hline 3 & - & - & $20.0^{c}$ & $0^{c}$ \\
\hline 7 & - & - & $20.0^{c}$ & $0^{\mathrm{c}}$ \\
\hline 14 & - & - & $20.0^{c}$ & $0^{\mathrm{c}}$ \\
\hline 29 & - & - & $10.0^{c}$ & $0^{\mathrm{c}}$ \\
\hline 58 & - & - & $10.0^{c}$ & $0^{\mathrm{c}}$ \\
\hline- & 100 & - & $20.0^{c}$ & $0^{c}$ \\
\hline- & 200 & - & $23.3^{c}$ & $0^{\mathrm{c}}$ \\
\hline- & - & 50 & $30.0^{c}$ & $0^{\mathrm{c}}$ \\
\hline- & - & 100 & $40.0^{\mathrm{bc}}$ & $0^{\mathrm{c}}$ \\
\hline
\end{tabular}

${ }^{x}$ Percentages of 30 explants within the same column followed by different letters are significantly different at $P \leq 0.001$ according to Chi-square

${ }^{y}$ Two separate cotyledons and a single radicle

\section{Multiple shoot-bud development}

Multiple shoot-bud development was observed on ten percent of zygotic embryos cultured under light (12-h photoperiod) on MS medium lacking growth regulators (Fig. 3). Approximately eight shoot-buds were produced per seedling. These multiplebud shoot developments were, however, not observed on any explants grown in the dark (data not shown). 


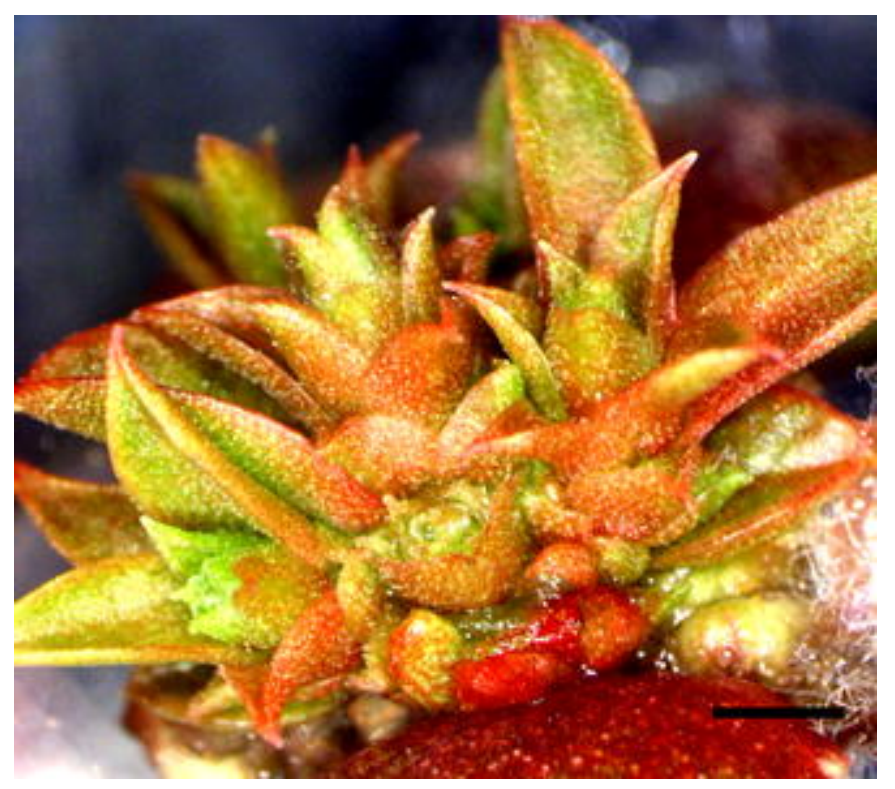

Fig. 3 Clusters of shoot-buds on cotyledons cultured on basal MS medium. Bar $\approx 5 \mathrm{~mm}$

\section{Discussion}

Results of this study showed the high competency of $P$. cynaroides zygotic explants to consistently form somatic embryos directly in medium lacking growth regulators, without an intervening callus phase. In addition, these results clearly showed that the addition of exogenous growth regulators, such as NAA, 2,4-D, TDZ, BAP and kinetin inhibited the induction of somatic embryos, while other additives such as casein hydrolysate and coconut water suppressed embryo induction. Inhibition or suppression of embryo induction by growth regulators is rare, since most research papers report the use of some sort of growth regulators (mostly auxins) for the induction of somatic embryos. These results strongly suggest that the source material (zygotic embryos and cotyledons) may be auxin-habituated and are predetermined to somatic embryogenesis (George 1993). Results from the direct formation of somatic embryos on zygotic embryos and cotyledons of $P$. cynaroides are in accordance with Sharp et al. (1980), where no auxin were required for somatic embryogenesis of the pre-embryogenic determined cells (PEDC). The PEDC were probably determined during a prior mitotic event in situ, before their transfer to a cell culture environment. Furthermore, in such cases, the process of embryogenesis is autonomous, and therefore, once embryo initiation has started, these cells are then able to 
fulfill their commitment to the embryogenic pattern of development, even in the absence of exogenous growth regulators. These embryos can continue to develop and germinate on the same medium without transferral to fresh medium (Sharp et al. 1980).

As mentioned earlier, research papers showing direct somatic embryo formation on growth medium lacking growth regulators are limited. Nevertheless, Gingas and Lineberger (1989) reported that in Quercus rubra, the highest percentage of somatic embryos was obtained from immature zygotic embryo tissues cultured on media lacking growth regulators. Similarly, Plata and Viéitez (1990) obtained somatic embryos on MS medium with no growth regulators from cotyledon sections and embryonic axis of Camellia reticulata, which completed their development on the same medium.

Although significantly fewer somatic embryos were formed in the dark on zygotic explants cultured on MS medium lacking growth regulators (Table 1), the ability of the explants to form embryos in both light and dark is noteworthy. This is similar to reports in Q. rubra, where embryos formed in both light and dark conditions, however, the highest number of somatic embryos was formed in light (Gingas and Lineberger 1989). In contrast, high irradiance inhibited embryogenesis in Glycine max (Lazzeri et al. 1987). Thus, it is possible that a promotion in the induction of somatic embryos could be affected by a different photoperiod or light intensity. Further research is needed to determine the relationship between different levels of light and the induction of somatic embryos in P. cynaroides.

Gibberellic acid is often used to stimulate the germination of somatic embryos in the post-initiation medium (George 1993). In this study, the lowest concentration $(0.3 \mu \mathrm{M})$ of $\mathrm{GA}_{3}$ promoted the germination of somatic embryos, and as the concentration increased, the germination percentage decreased. The $\mathrm{GA}_{3}$ concentration that promoted germination in this experiment is similar to that used in other studies. For instance, mostly in the range of 0.9-3 $\mu \mathrm{M} \mathrm{GA}_{3}$, germination of somatic embryos were successful in Vitis sp. (Mullins and Srinivasan 1976), Citrus sp. (Kochba et al. 1974) and Panicum maximum (Lu and Vasil 1982). However, there are also numerous papers reporting the germination of 
somatic embryos in media with no growth regulators, such as in Olea europaea (Rugini 1988), Dendranthema grandiflora. (May and Trigiano 1991), and Phragmites australis (Lauzer et al. 2000).

Incidences of malformed embryos were observed in all the medium treatments at the germination stage. The occurrence of malformed embryos seemed to be dependent on the concentration of growth regulators, particularly $\mathrm{GA}_{3}$, since the lowest concentration of $\mathrm{GA}_{3}(0.3 \mu \mathrm{M})$ produced the highest percentage of normal embryos, while as the $\mathrm{GA}_{3}$ concentration increased, the percentage of embryo malformation in P. cynaroides also increased. Thus, a possible remedy to further reduce the occurrence of malformed somatic embryos is to incorporate a lower amount of $\mathrm{GA}_{3}$ than currently used in this study. Another possible method is to include abscisic acid (ABA) into the medium. Manipulation of ABA concentrations has been shown to increase the frequency of embryos to reach maturity (Ammirato 1988). Its presence in the growth media has been reported to be essential for the healthy growth of somatic embryos, and credited with the elimination of abnormal forms of embryos (Ammirato 1973, 1974).

In the present study, the majority of zygotic embryos formed somatic embryos, while a few germinated into seedlings. However, from those zygotic embryos that did germinate, multiple shoot-bud developments were observed at the cotyledonary node region. This indicates the existence of totipotent cells at this particular region. Although these multiple shoot-buds developed in MS medium without growth regulators, it is often reported that cytokinins such as BAP added singly into the growth medium is required to induce multiple shoot development. Multiple shoot development from embryos has been reported in soybeans (Cheng et al. 1980) and almonds (Hisajima 1982). Further research is needed to establish the effects of cytokinins on the development of multiple shoot-buds in $P$. cynaroides.

\section{Conclusion}

This study has shown that zygotic explants possess a high competency to form somatic embryos, which can be germinated in media containing low concentrations of $\mathrm{GA}_{3}$ in the 
dark. The establishment of a protocol for direct somatic embryogenesis of $P$. cynaroides improves the prospects of producing Protea spp. quickly and efficiently. This is particularly important in a floriculture industry such as proteas where lengthy propagation time and inconsistent rooting is common, partly because seed and vegetative propagation, which have their limitations, are still the most commonly used methods for propagation. The relatively short period of time required to obtain germinated somatic embryos indicate that direct embryogenesis has great potential to be used in the mass production of $P$. cynaroides, as well as in plant breeding research. Further studies into the transfer of germinated somatic embryos to ex vitro conditions are needed. In addition, the development of multiple shoot-buds on the zygotic explant may be used as an alternative propagation method, but further research is needed.

\section{References}

Ammirato PV (1973) Some effects of abscisic acid on the development of embryos from caraway cells in suspension culture. Am J Bot 60(Suppl):22.

Ammirato PV (1974) The effects of abscisic acid on the development of somatic embryos from cells of caraway (Carum carvi L.). Bot Gaz 135:328-337.

Ammirato PV (1988) Role of ABA in regulation of somatic embryogenesis. HortScience $23: 520$.

Ben-Jaacov J, Jacobs G (1986) Establishing Protea, Leucospermum and Serruria in vitro. Acta Hort 185:39-52.

Cheng T-Y, Saka H, Voqui-Dinh TH (1980) Plant regeneration from soybean cotyledonary node segments in culture. Plant Sci Lett 19:91-99.

George EF (1993) Plant propagation by tissue culture. Part 1: In Theory. 2nd edn. Exegetics Ltd. Edington, Wilts. BA13 4QG, England. 
Gingas VM, Lineberger RD (1989) Asexual embryogenesis and plant regeneration in Quercus. Plant Cell Tiss Org Cult 17:191-203.

Hisajima S (1982) Multiple shoot formation from almond embryos. Biol Plant 24:235238.

Kochba J, Button J, Spiegel-Roy P, Bornman CH, Kochba M (1974) Stimulation of rooting of citrus embryoids by gibberellic acid and adenine sulphate. Ann Bot 38:795802.

Lauzer D, Dallaire S, Vincent G (2000) In vitro propagation of reed grass by somatic embryogenesis. Plant Cell Tiss Org Cult 60:229-234.

Lazzeri PA, Hildebrand DF, Collins GB (1987) Soybean somatic embryogenesis: Effects of nutritional, physical and chemical factors. Plant Cell Tiss Org Cult 10:209-220.

Lu C-Y, Vasil IK (1982) Somatic embryogenesis and plant regeneration in tissue cultures of Panicum maximum Jacq. Am J Bot 69:77-81.

May RA, Trigiano RN (1991) Somatic embryogenesis and plant regeneration from leaves of Dendranthema grandiflora. J Am Soc Hort Sci 116:366-371.

Mullins MG, Srinivasan C (1976) Somatic embryos and plantlets from an ancient clone of the grapevine. (cv. Cabernet-Sauvignon) by apoximis in vitro. J Exp Bot 27:10221030.

Murashige T, Skoog F (1962) A revised medium for rapid growth and bioassays with tobacco tissue cultures. Physiol Plant 15:473-497.

Plata E, Viéitez AM (1990) In vitro regeneration of Camellia reticulata by somatic embryogenesis. J Hort Sci 65:707-714. 
Rugge BA (1995) Micropropagation of Protea repens. Acta Hort 387:121-127.

Rugge BA, van der Merwe P, Jacobs G, Theron K (1989) Light microscopy of somatic embryogenesis from shoots of micropropagated Serruria florida (Proteaceae). Proc Microsc Soc S Afr 19:93-94.

Rugini E (1988) Somatic embryogenesis and plant regeneration in olive (Olea europaea L.). Plant Cell Tiss Org Cult 14:207-214.

SAS Institute Inc. (1996) The SAS system for Windows. SAS Institute Inc, SAS Campus drive, Cary, North Carolina, USA.

Sharp WR, Sondahl MR, Caldas LS, Maraffa SB (1980) The physiology of in vitro asexual embryogenesis. Hortl Rev 2:268-310.

Van Staden J, Choveaux NA, Gilliland MG, McDonald DJ, Davey JE (1981) Tissue culture of South African Proteacea. 1. Callus and proteoid rootlet formation on cotyledonary explants of Protea neriifolia. S Afr J Sci 77:493-495.

Wu HC (2006) Improving in vitro propagation of Protea cynaroides L. (King Protea) and the roles of starch and phenolic compounds in the rooting of cuttings. $\mathrm{PhD}$ thesis. Department of Plant Production and Soil Science, University of Pretoria, South Africa.

Wu HC, du Toit ES (2004) Reducing oxidative browning during in vitro establishment of Protea cynaroides. Sci Hort 100:355-358. 